\title{
Argyrophilic grain disease An update on a frequent cause of dementia
}

\author{
Lea T. Grinberg ${ }^{1,2}$, Helmut Heinsen ${ }^{2}$
}

\begin{abstract}
Argyrophilic grain disease (AGD) is a sporadic, very late-onset tauopathy, accounting for approximately $4-13 \%$ of neurodegenerative dementias. AGD may manifest with a range of symptoms such as cognitive decline and behavioral abnormalities. To date, no study has been able to demonstrate a distinct clinical syndrome associated with AGD. The diagnosis is exclusively based on postmortem findings, the significance of which remains controversial because up to $30 \%$ of AGD cases are diagnosed in subjects without any cognitive impairment, while AGD findings often overlap with those of other neurodegenerative processes. Nevertheless, the presence of AGD is likely to have a significant effect on cognitive decline. The neuropathological hallmarks of AGD are argyrophilic grains, pre-neurofibrillary tangles in neurons and coiled bodies in oligodendrocytes found mainly in the entorhinal cortex and hippocampus. This review aims to provide an up-to-date overview of AGD, emphasizing pathological aspects. Additionally, the findings of a Brazilian case series are described.
\end{abstract}

Key words: pathology, brain, neurology, argyrophilic grain disease, tau.

Doença com grãos argirofílicos: atualização sobre uma causa de demência muito prevalente

Resumo - Doença com grãos argirofílicos (DGA) é uma taupatia, não-familial, de início tardio que corresponde a cerca de 4 a 13\% das demências neurodegenerativas. DGA se manifesta com uma gama de sintomas como déficit cognitivo e distúrbios comportamentais. Até o momento, não se conhece nenhuma característica clínica que distinga DGA de outras demências. O diagnóstico é baseado nos achados anatomopatológicos, cujo significado é controverso, quer porque cerca de 30\% dos casos de DGA não apresentam sintomas, quer porque DGA é freqüentemente encontrada junto a outras alterações neurodegenerativas. Entretanto, acredita-se que a presença de DGA impacte a cognição. Os marcadores neuropatológicos de DGA são: grãos argirofílicos, pré-emaranhados neurofibrilares e corpúsculos em forma de vibrião em oligodendrócitos. As áreas mais afetadas são o córtex entorrinal, hipocampo e estruturas límbicas. Essa revisão almeja sumarizar o conhecimento mais atual sobre DGA e descrever brevemente achados de uma casuística brasileira.

Palavras-chave: patologia, encéfalo, neurologia, doença com grãos argirofílicos.

\section{Introduction and historical background}

Argyrophilic grain disease (AGD) is a very late-onset tauopathy, accounting for approximately $4-13 \%$ of neurodegenerative dementias. ${ }^{1-5}$ The name AGD stems from the argyrophilic structures characteristic of this entity.

AGD was first described in 1987 by Braak and colleagues as a distinctive degenerative disease characterized by argyrophilic grains confined to limbic structures affecting a subset of patients with adult onset dementia. ${ }^{6}$

Although highly prevalent, to date no study has been able to demonstrate a distinct clinical syndrome associated with AGD and only a few series have described clinical features that may correlate with the presence of this entity. ${ }^{7-12}$

The diagnosis is based solely on postmortem findings. The impact of the grains is controversial for two main reasons. Firstly, up to $30 \%$ of the AGD cases are diagnosed in subjects without any cognitive impairment. ${ }^{8,12}$ Secondly, AGD findings typically overlap with other neurodegenerative findings in cognitively impaired subjects, especially neurofibrillary tangles (NFT), one of the hallmark lesions of

${ }^{1} \mathrm{MD}$, PhD, Department of Pathology, University of São Paulo Medical School, São Paulo, SP, Brazil. ${ }^{2} \mathrm{MD}$ Labor fuer Morphologische Hirnforschung der Klinik und Poliklinik fuer Psychiatrie und Psychotherapie, University Of Wuerzburg, Wuerzburg, Germany.

Lea Tenenholz Grinberg - Department of Pathology Faculdade de Medicina da Universidade de São Paulo - Avenida Dr. Arnaldo, 455 / $1^{\text {st }}$ floor / room 1353 - 01246-903 São Paulo SP - Brazil.

Disclosure: The authors reports no conflicts of interest.

Received November 1, 2008. Accepted in final form February 5, 2009. 
Alzheimer's disease. ${ }^{8,9,13-16}$ The objective of this review was to provide an up-to-date overview of AGD and to describe the findings of a Brazilian case series drawn from the Brain Bank of the Brazilian Aging Brain Study Group (BBBABSG).

\section{Clinical symptoms}

AGD may manifest with a range of symptoms including cognitive decline, dementia ${ }^{4,7,15,17}$ and behavioral abnormalities. ${ }^{7,11,18,19}$

Amnestic cognitive impairment tends to be mild and non-progressive. ${ }^{9,20} \mathrm{~A}$ recent study verified that AGD patients retain abilities in verbalizing and articulating as well as problem-solving skills, on average, for approximately 2 years longer than Alzheimer's disease (AD) patients. However, there is no distinctive clinical profile for evaluating single cases. ${ }^{21}$

AGD may occasionally present as frontotemporal dementia, and is considered one of the possible neuropathological entities underlying frontotemporal dementia. ${ }^{22,23}$

Although the commonly associated AD pathology makes it difficult to assign specific clinical symptoms to AGD, the presence of AGD has a significant effect on cognitive decline; e.g. demented with AGD display considerably less $\mathrm{AD}$-associated pathology than pure $\mathrm{AD}$ would show at the same clinical stage. ${ }^{24,25}$
In summary, a precise test for clinical diagnosis of AGD has yet to be developed.

\section{Neuropathological aspects}

Gross examination of the brain shows moderate to severe cerebral atrophy with average brain weight of $1084 \pm 109 \mathrm{~g}$ up to $1120 \mathrm{~g} .{ }^{16}$

The neuropathological hallmarks of AGD are argyrophilic grains, pre-neurofibrillary tangles in neurons (pretangle neurons) and coiled bodies in oligodendrocytes. Given that all of these hallmarks are phospho-tau positive, AGD is classified as a tauopathy.

\section{Argyrophilic grains (AGs)}

The term is derived from their strong staining using the Gallyas silver iodide method. However, it is noteworthy that AGs are not stained by all silver methods ${ }^{26}$ indicating that AGs have specific features. AGs are also labeled using immunohistochemistry against phospho-tau protein, such as PHF-1 and AT8 antibodies (Figure 1A,B).

AGs occur mainly in transentorhinal, and entorhinal cortex, the CA1 area of the hippocampus and presubiculum. It is important to notice that these areas are also affected early by phospho-tau changes in AD. The adjoi-

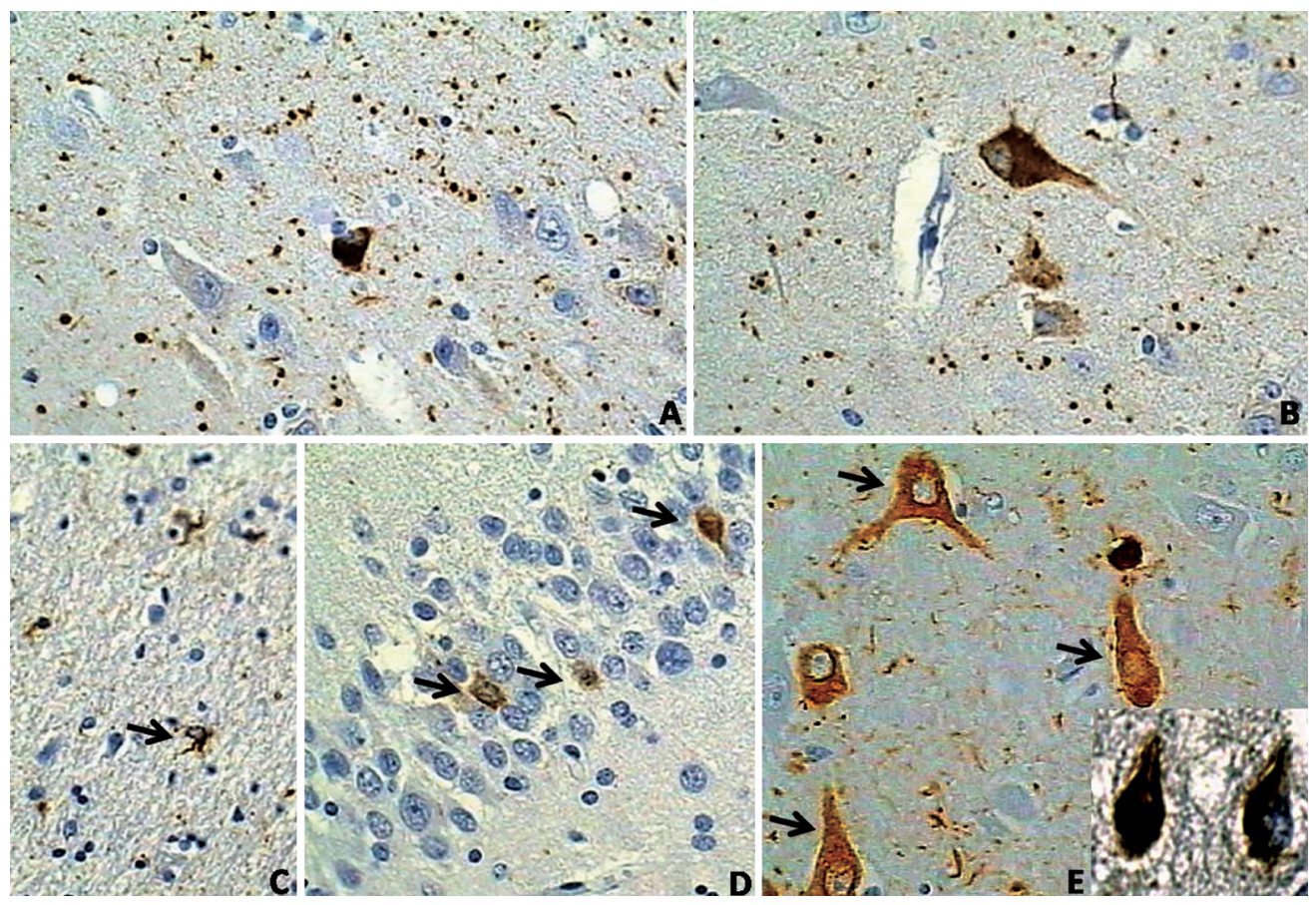

Figure 1. Neuropathological features of argyrophilic grain disease. All the histological slides are immunostained with PHF-1 antibody against phospho-tau. (A) Argyrophilic grains spread in the neuropil of region CA1 of the hippocampus. 400×. (B) The same as in A. Note a pre-tangle in the picture. $400 \times$. (C) Coiled body (arrow) in an oligodendrocyte in the white matter adjoining the entorhinal cortex. 400×. (D) Pre-tangles in the dentate gyrus (arrows). 400×. (E) Pre-tangles in the CA1 region of the hippocampus. Note the difference of the phospho-tau aspect between pre-tangles (diffuse) and the tangles (neurofibrillary) to the bottom right. 
ning temporal cortex, orbitofrontal cortex, insular cortex, basolateral nuclei of the amygdala and hypothalamic lateral tuberal nucleus can also be involved..$^{13,27}$ The source of AGs probably lies in pre-tangle projection neurons found in the same location as the $\mathrm{AGs}^{1,4}$. AGs are predominantly localized in dendrites and dendritic branches ${ }^{1,27,28}$, although association of AGs with axons has also been reported. ${ }^{4}$

AGs are small, about 4-8 micrometer, spindle shaped, rod-like, button-like or round bodies in the neuropil (Figure 1). Ultrastructurally, AGs contain straight filaments or tubules measuring $9-25 \mathrm{~nm} .{ }^{13}$

\section{Pre-tangle neurons (Figure 1B,D,E)}

Pre-tangle neurons are a constant finding in AGD, and their regional distribution is the same as that for AD. They are also found in the dentate gyrus (Figure 1D). ${ }^{4-6}$ Pre-tangle neurons in AGD do not apparently differ from pre-tangle neurons in $\mathrm{AD}^{29,30}$ (Figure 1B,D).

\section{Coiled bodies in oligodendrocytes}

Although being invariably found in AGD, coiled bodies are similar to those observed in many other tauopathies and therefore lack specificity. ${ }^{31,32}$ (Figure 1C).

\section{Other findings}

Tau-containing astrocytes - Astrocytes containing phospho-tau show granular immunoreactive cytoplasm rather than dense inclusions akin to those seen in tufted astrocytes in progressive supranuclear palsy. Generally, they appear in clusters, thus being suggestive of plaques seen in corticobasal degeneration. The presence of tau-containing astrocytes is variable from one case to another, and when found are usually confined to the limbic system.

Ballooned neurons - A- $\beta$-crystallin-positive ballooned neurons are commonly observed in the amygdala, in the presubiculum and middle layers of the basal temporal cortex in AGD. ${ }^{33}$ Yet ballooned neurons are usually interpreted as non-specific lesions, given these are a common finding in many familial and sporadic tauopathies and AD. ${ }^{34,35}$

Tangles and neuropil threads - Variable numbers of tangles and neuropil threads may be present in the same regions as in $\mathrm{AD}$. This has caused some confusion about the borderline between AGD with a few tangles and AGD with associated $\mathrm{AD} .{ }^{36}$ Most pathologists categorize $\mathrm{AD}$ changes (neurofibrillary tangles and neuropil threads) in AGD according to the guidelines of Braak and Braak. ${ }^{37}$

In their own case series Braak and colleagues classified most of the AGD cases as having AD ranging from stage from I to IV. ${ }^{18}$ However, the apparently small percentage of AGs in advanced stages of $\mathrm{AD}$ must be interpreted with care, as the substantial phospho-tau-immunoreactive pathology in such cases may incrementally hamper the visualization of AGs. Recent studies using 4R tau-specific antibodies which highlight AGs, have shown a higher prevalence of AGs in advanced stages of AD. ${ }^{38}$ Nevertheless, AGD is usually not accompanied by substantial $\beta$-amyloid deposits. $^{39}$

Staging of AGs - In 2004, Saito and colleagues proposed a staging system for AGD based on a refined analysis of a

Table 1. Comparison of the two neuropathological staging systems for argyrophilic grain disease, as proposed by Saito et al. in 2004 and Ferrer et al. in 2008.

\begin{tabular}{llllll}
\hline Staging & \multicolumn{4}{c}{ Stage } \\
\cline { 2 - 6 } system & I & II & & III & IV \\
\hline
\end{tabular}

Saito et al., Ambient gyrus and its vi- I + anterior and posterior II + septum, insular cor$2004^{2} \quad$ cinity medial temporal lobe, in- tex and anterior cingulate cluding the temporal pole, gyrus, and spongy degeneras well as the subiculum ation of the ambient gyrus and entorhinal cortex

Ferrer et al., Anterior entorhinal cor- more severe involvement of $2008^{5}$

tex; mild involvement of the nuclei involved in stage the cortical and basolateral I + Entorhinal and transennuclei of the amygdale and torhinal cortices; anterior of the hypothalamic lateral CA1 tuberal nucleus

II + mild involvement of Moderate to severe addi-
CA2, CA3, presubiculum; tional involvement of the
other nuclei of the amygda- neocortex and brainstem
la; dentate gyrus, other nu-
clei of the hypothalamus,
temporal, orbitofrontal and
insular cortices, cingulated
gyrus, ncl. accumbens, sep-
tal nuclei; midbrain


large series. ${ }^{2}$ This system presumes an antero-posterior progression of the disease. Rare cases have shown widespread AGs throughout the temporal lobe, limbic system, frontal cortex and brain stem. ${ }^{40-42}$ An up-dated staging system was proposed by Ferrer and colleagues in 2006. ${ }^{5}$ This recent systematic staging of AGs does not include accompanying changes. Table 1 compares the two staging systems.

\section{Biochemistry of tau in AGD}

Tau proteins are encoded by the tau gene on chromosome 17. Alternative splicing of exons 2, 3 and 10 results in six isoforms, which in turn give rise to six different mRNAs.

Tau proteins resulting from encoding exon 10 have four repeat regions ( $4 \mathrm{R}$ tau), whereas those lacking encoding exon 10 have three repeat regions ( $3 \mathrm{R}$ tau). ${ }^{43,44}$

The function of tau largely depends on post-translational modifications including phosphorylation and dephosphorylation, a balanced action between protein kinases and protein phosphatases. Several kinases have been implicated in tau phosphorylation. ${ }^{45-50}$

In contrast to $\mathrm{AD}$, in which $3 \mathrm{R}$ tau and $4 \mathrm{R}$ tau forms are found, AGD is characterized by a double band of 68 and 64 $\mathrm{kDa}$ similar to that found in progressive supranuclear palsy and corticobasal degeneration. Therefore, AGD is considered a $4 \mathrm{R}$ tauopathy. The use of specific anti- $4 \mathrm{R}$ antibodies has corroborated this biochemical observation. ${ }^{51}$

Interestingly, the occurrence of tangles and pre-tangles in the hippocampal CA2 area, a very common finding in AGD, is associated with $4 \mathrm{R}$ tauopathy. ${ }^{52}$

\section{Genetics}

AGD appears to be sporadic given that a familial form has yet to be reported. The tau gene or microtubule-associated protein tau (MAPT) locus is located on chromosome $17 \mathrm{q} 21 .{ }^{53}$ The region is divided into two predominant haplotypes, $\mathrm{H} 1$ and $\mathrm{H} 2$. In 2008, a single case with AGD phenotype was linked to a novel S305I MAPT mutation and $^{54}$ there is evidence from one series that the incidence of MAPT $\mathrm{H} 1$ is slightly higher in AD cases with AGD than in those without AGD. ${ }^{38}$ However, other genetic studies have failed to discover a sustained link between AGD and a particular gene locus. The frequency of apolipoprotein $\mathrm{E}$ e4 (ApoE e4) allele, the most important genetic risk for $\mathrm{AD}$, proves similar to that of the general population in cases of AGD. ${ }^{55}$ Nevertheless, the frequency of ApoE e2 is higher in AGD than that observed in both AD or controls. ${ }^{51,56}$

\section{Differential diagnosis}

Neuropathological studies have shown frequent association of AGD with other neurodegenerative diseases, the most common being AD. AGD has also been reported to- gether with other tauopathies, Creutzfeldt-Jakob disease, $\alpha$-synucleinopathies and hippocampal sclerosis. ${ }^{8,16,18,57-60}$

\section{AGD in the case series from the Brain Bank of the Brazilian Aging Brain Study Group}

In the BBBABSG series, AGD was diagnosed in 36 $(11.5 \%)$ out of the first 307 fully analyzed cases. In accordance with other series, AGD was more frequently found in older subjects $(p<0.05)$. No statistically significant difference was found concerning gender, years of schooling, cognitive status, Braak and Braak neurofibrillary stage, presence of $\beta$-amyloid plaques or Lewy bodies among the cases with and without AGD. Most interestingly, AGD was the only finding in $14.3 \%$ of the subjects manifesting moderate or severe parkinsonism signs. Although AGD is not classically associated with parkinsonism, we are not the first to report this association. ${ }^{61}$ AGD is usually associated with finding of allocortical neurofibrillary tangles. Accordingly, in our series only two AGD cases (6.9\%) were devoid of tangles. One of these subjects, a 79-year-old male had no cognitive decline, whereas the other subject, a 82-year-old female showed severe dementia, interpreted as being attributed to the severe burden of microvascular changes and lacunes rather than the presence of AGs.

\section{Conclusions}

AGD is a sporadic and distinct tauopathy often found in the brain of older subjects. Although linked to cognitive decline, behavioral problems and even parkinsonism, no study to date has demonstrated any clinical or laboratory particularity able to distinguish AGD from other neurodegenerative diseases, while several subjects harboring AGD appear not to be demented. In recent years, studies based on well-conducted clinicopathological correlation series have pointed to older age as the only risk factor for AGD, and revealed that AGD may lower the threshold for dementia. Neither of these findings was observed in our series.

Several points still remain obscure. What is the origin of the grains? Is AGD a distinct clinical syndrome? How can neurofibrillary tangles of Alzheimer disease be differentiated from those found in AGD? Is there any hallmark clinical symptom suggestive of the presence of AGs in the brain? Additional comprehensive, prospective clinicopathological correlation studies are required to answer many of these questions.

Acknowledgement - We would like to thank the Brazilian Aging Brain Study Group for their unconditional support. LTG is a recipient of the Alexander von Humboldt foundation's Georg Foster scholarship. Grant support to LTG: Alexander von Humboldt Foundation. 


\section{References}

1. Tolnay M, Mistl C, Ipsen S, Probst A. Argyrophilic grains of Braak: occurrence in dendrites of neurons containing hyperphosphorylated tau protein. Neuropathol Appl Neurobiol 1998;24:53-59.

2. Saito Y, Ruberu NN, Sawabe M, et al. Staging of argyrophilic grains: an age-associated tauopathy. J Neuropathol Exp Neurol. 2004;63:911-918.

3. Ding ZT, Wang Y, Jiang YP, et al. Argyrophilic grain disease: frequency and neuropathology in centenarians. Acta Neuropathol. 2006;111:320-328.

4. Tolnay M, Clavaguera F. Argyrophilic grain disease: a lateonset dementia with distinctive features among tauopathies. Neuropathology 2004;24:269-283.

5. Ferrer I, Santpere G, van Leeuwen FW. Argyrophilic grain disease. Brain 2008;131:1416-1432.

6. Braak H, Braak E. Argyrophilic grains: characteristic pathology of cerebral cortex in cases of adult onset dementia without Alzheimer changes. Neurosci Lett 1987;76:124-127.

7. Ikeda K, Akiyama H, Arai T, Matsushita M, Tsuchiya K, Miyazaki $\mathrm{H}$. Clinical aspects of argyrophilic grain disease. Clin Neuropathol. 2000;19:278-284.

8. Martinez-Lage P, Munoz DG. Prevalence and disease associations of argyrophilic grains of Braak. J Neuropathol Exp Neurol 1997;56:157-164.

9. Jicha GA, Petersen RC, Knopman DS, et al. Argyrophilic grain disease in demented subjects presenting initially with amnestic mild cognitive impairment. J Neuropathol Exp Neurol 2006;65:602-609.

10. Botez G, Schultz C, Ghebremedhin E, Bohl J, Braak E, Braak $\mathrm{H}$. Clinical aspects of argyrophilic grain disease. Nervenarzt 2000;71:38-43.

11. Togo T, Isojima D, Akatsu $\mathrm{H}$, et al. Clinical features of argyrophilic grain disease: a retrospective survey of cases with neuropsychiatric symptoms. Am J Geriatr Psychiatry 2005;13: 1083-1091.

12. Tolnay M, Schwietert M, Monsch AU, Staehelin HB, Langui D, Probst A. Argyrophilic grain disease: distribution of grains in patients with and without dementia. Acta Neuropathol 1997;94:353-358.

13. Braak H, Braak E. Cortical and subcortical argyrophilic grains characterize a disease associated with adult onset dementia. Neuropathol Appl Neurobiol 1989;15:13-26.

14. Knopman DS, Parisi JE, Salviati A, et al. Neuropathology of cognitively normal elderly. J Neuropathol Exp Neurol 2003;62: 1087-1095.

15. Togo T, Cookson N, Dickson DW. Argyrophilic grain disease: neuropathology, frequency in a dementia brain bank and lack of relationship with apolipoprotein E. Brain Pathol 2002;12:45-52.

16. Jellinger KA. Dementia with grains (argyrophilic grain disease). Brain Pathol. 1998;8:377-386.
17. Saito Y, Yamazaki M, Kanazawa I, Murayama S. Severe involvement of the ambient gyrus in a case of dementia with argyrophilic grain disease. J Neurol Sci 2002;196:71-75.

18. Braak H, Braak E. Argyrophilic grain disease: frequency of occurrence in different age categories and neuropathological diagnostic criteria. J Neural Transm 1998;105:801-819.

19. Cairns NJ, Grinberg LT, Lisic R, et al. Expanding the neuropathological spectrum of frontotemporal lobar degenerations: review of 833 prospectively assessed dementia cases. J Neural Transm 2006;113:7.

20. Petersen RC, Parisi JE, Dickson DW, et al. Neuropathologic features of amnestic mild cognitive impairment. Arch Neurol 2006;63:665-672.

21. Steuerwald GM, Baumann TP, Taylor KI, et al. Clinical characteristics of dementia associated with argyrophilic grain disease. Dement Geriatr Cogn Disord 2007;24:229-234.

22. Kovacs GG, Pittman A, Revesz T, et al. MAPT S305I mutation: implications for argyrophilic grain disease. Acta Neuropathol 2008;116:103-118.

23. Cairns NJ, Bigio EH, Mackenzie IR, et al. Neuropathologic diagnostic and nosologic criteria for frontotemporal lobar degeneration: consensus of the Consortium for Frontotemporal Lobar Degeneration. Acta Neuropathol 2007;114:5-22.

24. Thal DR, Schultz C, Botez G, et al. The impact of argyrophilic grain disease on the development of dementia and its relationship to concurrent Alzheimer's disease-related pathology. Neuropathol Appl Neurobiol 2005;31:270-279.

25. Josephs KA, Whitwell JL, Parisi JE, et al. Argyrophilic grains: a distinct disease or an additive pathology? Neurobiol Aging 2008;29:566-573.

26. Uchihara T. Silver diagnosis in neuropathology: principles, practice and revised interpretation. Acta Neuropathol 2007; 113:483-499.

27. Schultz C, Koppers D, Sassin I, Braak E, Braak H. Cytoskeletal alterations in the human tuberal hypothalamus related to argyrophilic grain disease. Acta Neuropathol 1998;96: 596-602.

28. Ikeda K, Akiyama H, Kondo H, Haga C. A study of dementia with argyrophilic grains: possible cytoskeletal abnormality in dendrospinal portion of neurons and oligodendroglia. Acta Neuropathol 1995;89:409-414.

29. Braak E, Braak H, Mandelkow EM. A sequence of cytoskeleton changes related to the formation of neurofibrillary tangles and neuropil threads. Acta Neuropathol 1994;87:554-567.

30. Tau and ubiquitin immunoreactivity at different stages of formation of Alzheimer neurofibrillary tangles. New York: Alan R. Liss; 1989.

31. Komori T. Tau-positive glial inclusions in progressive supranuclear palsy, corticobasal degeneration and Pick's disease. Brain Pathol 1999;9:663-679.

32. Ikeda K, Akiyama H, Arai T, Nishimura T. Glial tau pathol- 
ogy in neurodegenerative diseases: their nature and comparison with neuronal tangles. Neurobiol Aging 1998;19(1 Suppl):S85-91.

33. Tolnay M, Villoz N, Probst A, Miserez AR. Apolipoprotein E genotype in senile dementia with tangles differs from Alzheimer's disease. Neuropathol Appl Neurobiol 2003;29: 80-84.

34. Fujino Y, Delucia MW, Davies P, Dickson DW. Ballooned neurones in the limbic lobe are associated with Alzheimer type pathology and lack diagnostic specificity. Neuropathol Appl Neurobiol 2004;30:676-682.

35. Togo T, Dickson DW. Ballooned neurons in progressive supranuclear palsy are usually due to concurrent argyrophilic grain disease. Acta Neuropathol 2002;104:53-56.

36. Cras P, Perry G. Dementia with argyrophilic grains. Ann Neurol 1991;30:853-854.

37. Braak H, Braak E. Neuropathological stageing of Alzheimerrelated changes. Acta Neuropathol. 1991;82:239-259.

38. Fujino Y, Wang DS, Thomas N, Espinoza M, Davies P, Dickson DW. Increased frequency of argyrophilic grain disease in Alzheimer disease with $4 \mathrm{R}$ tau-specific immunohistochemistry. J Neuropathol Exp Neurol 2005;64:209-214.

39. Tolnay M, Calhoun M, Pham HC, Egensperger R, Probst A. Low amyloid (Abeta) plaque load and relative predominance of diffuse plaques distinguish argyrophilic grain disease from Alzheimer's disease. Neuropathol Appl Neurobiol 1999;25:295-305.

40. Tsuchiya K, Mitani K, Arai T, et al. Argyrophilic grain disease mimicking temporal Pick's disease: a clinical, radiological, and pathological study of an autopsy case with a clinical course of 15 years. Acta Neuropathol 2001;102:195-199.

41. Maurage CA, Sergeant N, Schraen-Maschke S, et al. Diffuse form of argyrophilic grain disease: a new variant of fourrepeat tauopathy different from limbic argyrophilic grain disease. Acta Neuropathol 2003;106:575-583.

42. Ishihara K, Araki S, Ihori N, et al. Argyrophilic grain disease presenting with frontotemporal dementia: a neuropsychological and pathological study of an autopsied case with presenile onset. Neuropathology 2005;25:165-170.

43. Goedert M, Spillantini MG, Jakes R, Rutherford D, Crowther RA. Multiple isoforms of human microtubule-associated protein tau: sequences and localization in neurofibrillary tangles of Alzheimer's disease. Neuron 1989;3:519-526.

44. Himmler A, Drechsel D, Kirschner MW, Martin Jr DW. Tau consists of a set of proteins with repeated C-terminal microtubule-binding domains and variable N-terminal domains. Mol Cell Biol 1989;9:1381-1388.

45. Hanger DP, Mann DM, Neary D, Anderton BH. Tau pathology in a case of familial Alzheimer's disease with a valine to glycine mutation at position 717 in the amyloid precursor protein. Neurosci Lett 1992;145:178-180.

46. Mandelkow E, Mandelkow EM. Kinesin motors and disease. Trends Cell Biol. 2002;12:585-591.

47. Goedert M, Spillantini MG, Davies SW. Filamentous nerve cell inclusions in neurodegenerative diseases. Curr Opin Neurobiol 1998;8:619-632.

48. Lovestone S, Reynolds $\mathrm{CH}$. The phosphorylation of tau: a critical stage in neurodevelopment and neurodegenerative processes. Neuroscience 1997;78:309-324.

49. Reynolds CH, Nebreda AR, Gibb GM, Utton MA, Anderton $\mathrm{BH}$. Reactivating kinase/p38 phosphorylates tau protein in vitro. J Neurochem 1997;69:191-198.

50. Reynolds CH, Utton MA, Gibb GM, Yates A, Anderton BH. Stress-activated protein kinase/c-jun N-terminal kinase phosphorylates tau protein. J Neurochem 1997;68:1736-1744.

51. Togo T, Sahara N, Yen SH, et al. Argyrophilic grain disease is a sporadic 4-repeat tauopathy. J Neuropathol Exp Neurol 2002;61:547-556.

52. Ishizawa T, Ko LW, Cookson N, Davias P, Espinoza M, Dickson DW. Selective neurofibrillary degeneration of the hippocampal CA2 sector is associated with four-repeat tauopathies. J Neuropathol Exp Neurol 2002;61:1040-1047

53. Andreadis, A, Brown, WM, Kosik, KS. Structure and novel exons of the human tau gene. Biochemistry (Mosc.). 1992;31: 10626-10633.

54. Kovacs GG, Pittman A, Revesz T, et al. MAPT S305I mutation: implications for argyrophilic grain disease. Acta Neuropathol 2008;116:103-118

55. Tolnay M, Probst A, Monsch AU, Staehelin HB, Egensperger R. Apolipoprotein E allele frequencies in argyrophilic grain disease. Acta Neuropathol 1998;96:225-227.

56. Ghebremedhin E, Schultz C, Botez G, et al. Argyrophilic grain disease is associated with apolipoprotein E epsilon 2 allele. Acta Neuropathol. 1998;96:222-224.

57. Ferrer I, Barrachina M, Tolnay M, et al. Phosphorylated protein kinases associated with neuronal and glial tau deposits in argyrophilic grain disease. Brain Pathol 2003;13:62-78.

58. Masliah E, Hansen LA, Quijada S, et al. Late onset dementia with argyrophilic grains and subcortical tangles or atypical progressive supranuclear palsy? Ann Neurol 1991;29:389-396.

59. Ikeda K, Akiyama H, Kondo H, et al. Thorn-shaped astrocytes: possibly secondarily induced tau- positive glial fibrillary tangles. Acta Neuropathol 1995;90:620-625.

60. Beach TG, Sue L, Scott S, et al. Hippocampal sclerosis dementia with tauopathy. Brain Pathol 2003;13:263-278.

61. Uchikado H, Tsuchiya K, Tominaga I, et al. Argyrophilic grain disease clinically mimicking Parkinson's disease with dementia: report of an autopsy case. No To Shinkei 2004;56:785-788. 